\title{
Safety of Levetiracetam in Paediatrics: A Systematic Review
}

\author{
Oluwaseun Egunsola*, Imti Choonara, Helen Mary Sammons \\ Division of Medical Sciences and Graduate Entry Medicine, School of Medicine, University of Nottingham, \\ Royal Derby Hospital, Derby, DE22 3DT, United Kingdom \\ *mzxoe@nottingham.ac.uk
}

\section{Abstract}

\section{Objective}

To identify adverse events (AEs) associated with Levetiracetam (LEV) in children.

\section{G open access}

Citation: Egunsola O, Choonara I, Sammons HM (2016) Safety of Levetiracetam in Paediatrics: A Systematic Review. PLoS ONE 11(3): e0149686. doi:10.1371/journal.pone. 0149686

Editor: Thimmasettappa Thippeswamy, lowa State University, UNITED STATES

Received: October 6, 2015

Accepted: February 2, 2016

Published: March 1, 2016

Copyright: @ 2016 Egunsola et al. This is an open access article distributed under the terms of the Creative Commons Attribution License, which permits unrestricted use, distribution, and reproduction in any medium, provided the original author and source are credited.

Data Availability Statement: All relevant data are within the paper and its Supporting Information files.

Funding: $\mathrm{OE}$ received $\mathrm{PhD}$ funding from the commonwealth Scholarship Commission (http:// cscuk.dfid.gov.uk). The funders had no role in study design, data collection and analysis, decision to publish, or preparation of the manuscript.

Competing Interests: IC is an Academic Editor for PlosoNe. This does not alter the authors' adherence to PLOS ONE policies on sharing data and materials.

\section{Methods}

Databases EMBASE (1974-February 2015) and Medline (1946-February 2015) were searched for articles in which paediatric patients ( $\leq 18$ years) received LEV treatment for epilepsy. All studies with reports on safety were included. Studies involving adults, mixed age population (i.e. children and adults) in which the paediatric subpopulation was not sufficiently described, were excluded. A meta-analysis of the RCTs was carried out and association between the commonly reported AEs or treatment discontinuation and the type of regimen (polytherapy or monotherapy) was determined using $\mathrm{Chi}^{2}$ analysis.

\section{Results}

Sixty seven articles involving 3,174 paediatric patients were identified. A total of 1,913 AEs were reported across studies. The most common AEs were behavioural problems and somnolence, which accounted for $10.9 \%$ and $8.4 \%$ of all AEs in prospective studies. 21 prospective studies involving 1120 children stated the number of children experiencing AEs. $47 \%$ of these children experienced AEs. Significantly more children experienced AEs with polytherapy $(64 \%)$ than monotherapy $(22 \%)(p<0.001)$. Levetiracetam was discontinued in $4.5 \%$ of all children on polytherapy and $0.9 \%$ on monotherapy $(p<0.001)$, the majority were due to behavioural problems.

\section{Conclusion}

Behavioural problems and somnolence were the most prevalent adverse events to LEV and the most common causes of treatment discontinuation. Children on polytherapy have a greater risk of adverse events than those receiving monotherapy. 


\section{Introduction}

Levetiracetam (LEV) is one of the most commonly prescribed new generation antiepileptic drugs (AEDs). It accounts for about $8 \%$ of paediatric AED prescriptions in the UK [1] and 7\% in Germany [2] and Hong Kong [3]. It was approved for adult use in Europe in 2000 and subsequently for paediatric use in 2005[4]. In the UK, it is recommended as an adjunctive agent for partial seizures, myoclonic seizures as well as for some epilepsy syndromes such as: rolandic epilepsy and late-onset childhood occipital epilepsy [5]. Some of the adverse reactions commonly associated with LEV include: somnolence, dizziness and behavioural problems. Behavioural problems are more commonly reported in children than adults [6].

LEV undergoes elimination predominantly by renal excretion. Metabolism by hydrolysis and hydroxylation is a minor process. This is thought to reduce the risk of drug-drug interactions [7]. Its onset of action is rapid, which makes it a candidate drug for the treatment of status epilepticus [8].Levetiracetam is approved for use in children as adjunctive therapy. It can be prescribed as monotherapy to adolescents 16 years old and over. Although, the safety of the drug in children and adolescents less than 16 years old is unknown, monotherapy use in this population is quite common [6].

Due to the increasing utilisation of LEV in children, this systematic review aims to evaluate the available evidence, from all studies, on the safety of LEV in children.

\section{Method}

This review was carried out as per PRISMA guidelines. The systematic review protocol was not published

\section{Search strategy}

Databases EMBASE (1974- February 2015) and Medline (1946-February 2015) were searched for articles in which paediatric patients ( $\leq 18$ years) received LEV treatment for epilepsy. The paediatric search terms used were: paediatric* or pediatric* or boy* or girl* or pediatric ${ }^{*}$ or child* $^{*}$ or neonat* ${ }^{*}$ infan* or adolescen* or newborn* or baby or toddler or young, in title [9]. This was combined with levetiracetam, also in title. Output was limited to humans and journal articles. Only studies that evaluated and reported safety outcomes were included. Papers published in English, Chinese, French and Spanish were included. Studies involving adults, mixed age population (i.e. children and adults) in which the paediatric subpopulation was not sufficiently described, were excluded.

\section{Data extraction}

The types and number of AEs were extracted. Other extracted data included: the age of the patients, the dose, route of administration, the number of study participants, co-administered drugs, type of regimen (monotherapy or polytherapy) and the duration of follow up. Adverse reactions resulting in the discontinuation of LEV treatment were also documented

\section{Data quality assessment}

The quality of the RCTs were assessed using the Cochrane collaboration's tool for assessing risk of bias in randomised trials [10]. The quality of the prospective observational studies were assessed using the System for the Unified Management of the Review and Assessment of Information (SUMARI)[11]. Data from any study fulfilling 4 or more of the 9 criteria were included in the final data aggregation ( $\mathrm{S} 1$ appendix). All studies were independently assessed by two 
reviewers. Any conflicting outcomes were discussed between the reviewers before a verdict was agreed upon.

\section{Data collection and statistical analysis}

A meta-analysis of the RCTs was done using Revman version 6. Only AEs identified from 2 or more studies were analysed. The relative risks of AEs present in at least two RCTs were calculated, with a RR $>1$ suggesting that more AE were associated with LEV treatment. The data were considered homogeneous $\mathrm{I}^{2} \leq 50 \%$ or $\mathrm{Chi}^{2} \mathrm{p} \geq 0.05$. Homogeneous data were analysed using the fixed effect model while the random effect model was used for heterogeneous data. Risk of AEs per 100 patient was also determined in both prospective and retrospective studies. $\mathrm{Chi}^{2}$ analysis of the association between each AE and the treatment regimen (polytherapy or monotherapy) was performed. $\mathrm{Chi}^{2}$ analysis of the association between treatment discontinuation and the treatment regimen was also conducted. P-values $<0.05$ were considered statistically significant for all analyses.

\section{Results \\ Description of study characteristics}

Sixty seven articles involving 3,174 paediatric patients were identified (Fig 1). No RCT or prospective cohort study was excluded after quality analysis (Fig 2). Quality analysis was not performed for retrospective studies. A total of 1,913 AEs were reported across studies. The largest numbers of children $(1,461)$ were recruited within the 21 retrospective studies (Table 1$)$. The greatest number of AEs (897) however was reported in the 20 prospective cohort studies. There were 6 RCTs with 415 reports of AEs.

The median period of follow-up was 24 weeks [IQR: 16.5-51 weeks]. Levetiracetam was administered orally in the majority of the studies (32 studies). In 8 studies, it was given intravenously; while both IV and oral LEV were administered in one study. Another study used a combination of IV, oral, rectal and nasogastric tube administration. The route of administration was not indicated in 8 studies. In 22 studies, LEV was given as an adjunct to other AEDs; while it was administered alone in 19 of the studies. Combinations of monotherapy and polytherapy regimen were given in 10 studies.

\section{Levetiracetam dosing}

Levetiracetam dose was titrated in all studies. The median initial dose was $10 \mathrm{mg} / \mathrm{kg} /$ day [IQR: 10-14]; while the median final dose was $60 \mathrm{mg} / \mathrm{kg} /$ day [IQR: 40-60]. There was no significant difference $(\mathrm{p}=0.986)$ between the median initial dose in polytherapy $(10 \mathrm{mg} / \mathrm{kg} / \mathrm{day}$ [IQR: $10-$ $20]$ ) and monotherapy studies (10mg/kg/day [IQR: 10-10.5]). The median final dose in polytherapy studies $(60 \mathrm{mg} / \mathrm{kg} /$ day [IQR: 60-61.5]) was however significantly higher $(\mathrm{p}=0.003)$ than in monotherapy studies (30mg/kg/day [IQR: $35-52.5]$ ).

\section{Evidence from Randomised controlled trials}

Six RCTs were identified, 4 of which were placebo controlled trials (Table 2). Three of the 6 studies were monotherapy studies comparing LEV treatment with sulthiame (STM), oxcarbazepine (OXC) and placebo respectively. In one study, airway problems (AEs not specified) were significantly more with STM than LEV [12]. None of the other studies reported any significant difference in AEs.

The three polytherapy studies were add-on placebo controlled studies. Although there was a twofold increase in risk of abnormal behaviour in LEV treated children versus placebo [RR: 

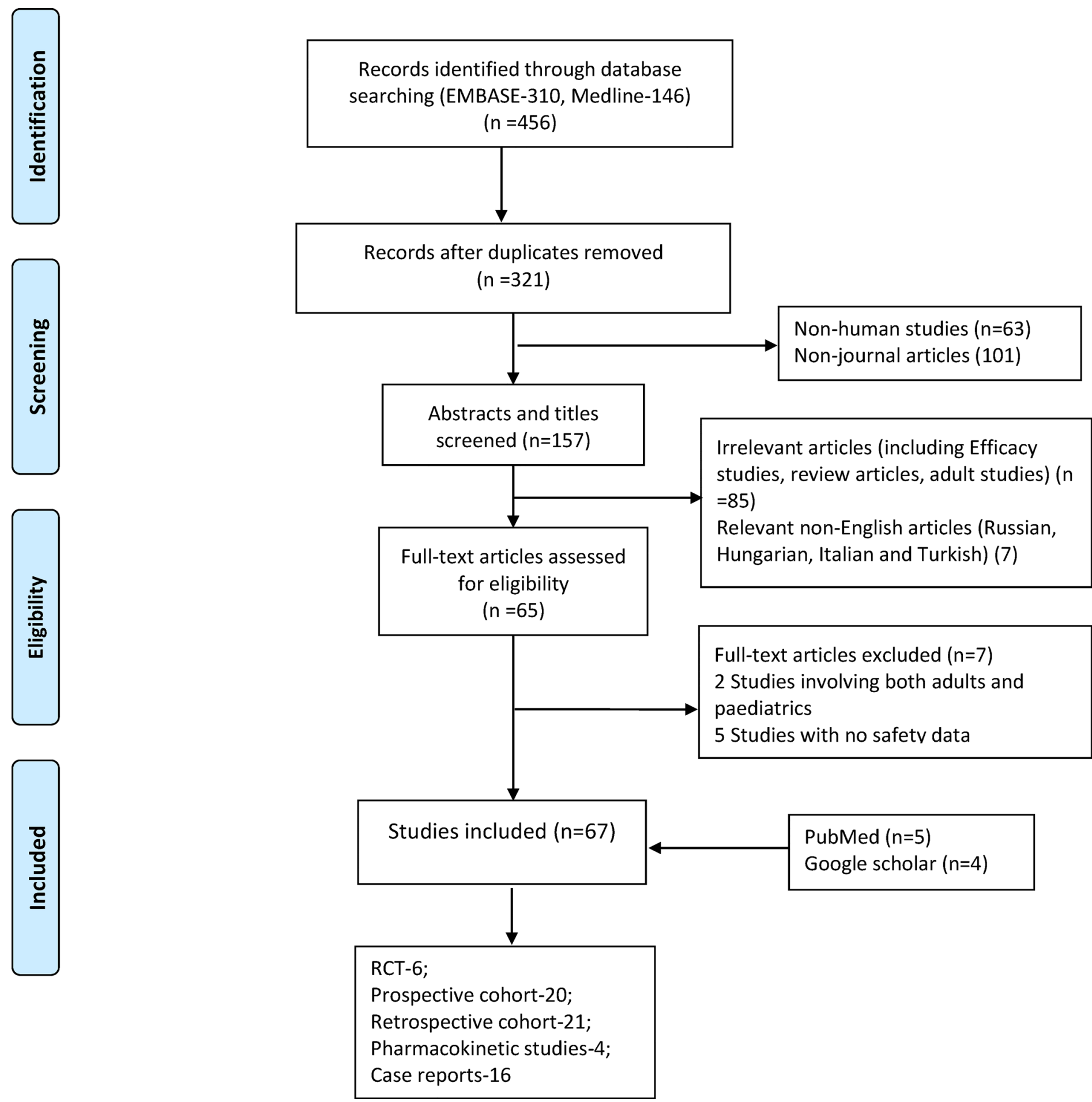

Fig 1. Flow chart of included studies.

doi:10.1371/journal.pone.0149686.g001

1.92 95\%CI: $1.01-3.63$ ], this did not reach statistical significance $(\mathrm{p}=0.05)$. Twelve percent of children on LEV developed abnormal behaviours such as: aggression, irritability and hyperactivity; compared to $6 \%$ of those on placebo. There was also an increase in the risk of 

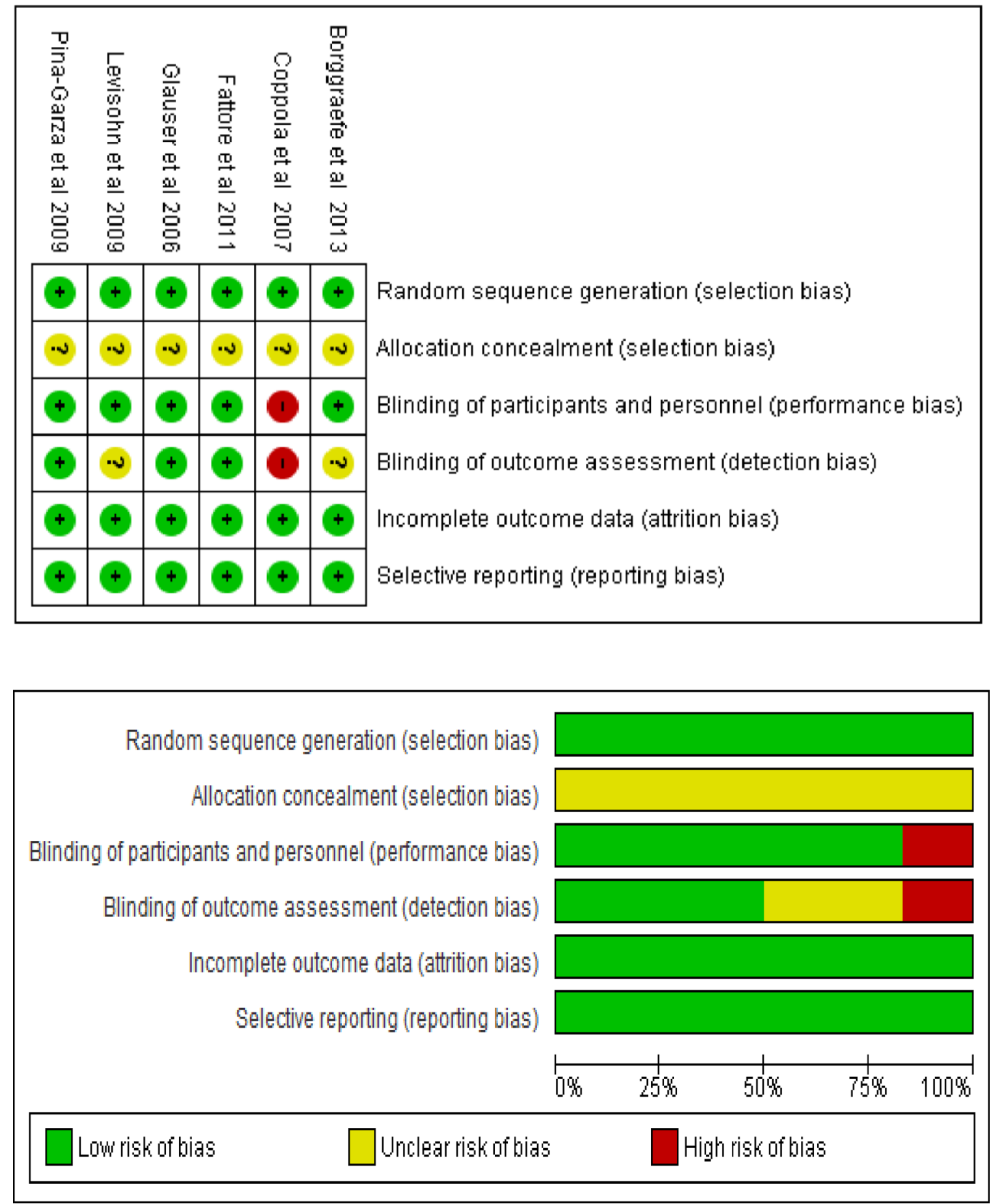

Fig 2. Risk of bias summary and graph.

doi:10.1371/journal.pone.0149686.g002

somnolence in LEV treated children compared with placebo [RR: 2.24, 95\%CI: 1.29-3.86, $\mathrm{p}=0.004$ ], about $18 \%$ vs. $8 \%$ respectively. About $8.5 \%$ of LEV treated children had reports of anxiety compared with $1.5 \%$ of placebo, representing a significant increase [RR: $4.81,95 \% \mathrm{CI}$ : 
Table 1. Summary of included studies.

\begin{tabular}{llll}
\hline Study type & Number of studies & Number of AEs (\%) & Number of patients (\%) \\
\hline RCTs & 6 & 415 & $306(10 \%)$ \\
Prospective cohort studies & 20 & 897 & $1311(41 \%)$ \\
Pharmacokinetic studies & 4 & 32 & $73(2 \%)$ \\
Retrospective cohort studies & 21 & 546 & $1461(46 \%)$ \\
Case reports & 16 & 23 & $23(1 \%)$ \\
Total & $\mathbf{6 7}$ & $\mathbf{1 9 1 3}$ & $\mathbf{3 1 7 4}$ \\
\hline
\end{tabular}

doi:10.1371/journal.pone.0149686.t001

1.27-18.20, $\mathrm{p}=0.02$ ] (Fig 3). There was no significant difference in the risks of other commonly reported AEs such as loss of appetite, vomiting, dizziness, rash and insomnia (Fig 3).

\section{Evidence from prospective studies}

Prospective studies included prospective cohort studies, RCTs and PK studies and included 1690 children (Tables 2 and 3). 21 of the 30 studies stated the number of children who experienced AEs and included 1120 children. A total of 995 AEs were reported in 525 children (47\%). The majority (26\%) of the AEs were psychiatric events. Behavioural problems accounted for $64 \%$ of all psychiatric events. $10.9 \%$ of all AEs were behavioural problems. Common ones included: aggression, irritability and hyperactivity. In several studies, the form of the behavioural problem was not reported. Neurological AEs were also frequently reported, accounting for $24 \%$ of AEs. Somnolence was the most common neurological AE (Table 4) occurring in $8.4 \%$ of children. Common $(\geq 1 / 100$ to $<1 / 10)$ neurological events included: headache, dizziness and drowsiness. Vomiting, abdominal pain and diarrhoea were the commonly reported gastrointestinal events. 12\% of AEs were gastrointestinal (Table C in S1 Table).

There were 7 prospective studies involving 229 paediatric patients where it was possible to determine the number of children with AEs following LEV monotherapy. Fifty one (22\%) of these children had at least one $\mathrm{AE}$. There were 10 prospective studies involving 613 paediatric patients on polytherapy and 392 children $(64 \%)$ had at least one AE. Polytherapy was associated with a significantly higher rate of AEs $(\mathrm{p}<0.001)$. There were 82 children who experienced AEs where it was not possible to determine whether they were on polytherapy or monotherapy.

Table 2. Data summary for Randomised controlled trials.

\begin{tabular}{|c|c|c|c|c|c|c|c|c|c|}
\hline Reference & $\begin{array}{l}\text { No receiving } \\
\text { LEV }\end{array}$ & Comparator & $\begin{array}{l}\text { Age } \\
\text { (yrs) }\end{array}$ & $\begin{array}{l}\text { Initial dose } \\
\text { (mg/kg/day) }\end{array}$ & $\begin{array}{l}\text { Final dose [mean] } \\
\text { (mg/kg/d) }\end{array}$ & Route & Regimen & $\begin{array}{l}\text { No of } \\
\text { AEs }\end{array}$ & $\begin{array}{l}\text { Follow-up } \\
\text { (wks) }\end{array}$ \\
\hline $\begin{array}{l}\text { Borgraeffe et al, } \\
2013[12]\end{array}$ & 22 & Sulthiame & $6-12$ & 10 & 30 & Oral & Monotherapy & $64^{*}$ & 24 \\
\hline $\begin{array}{l}\text { Fattore et al, } 2011 \\
\text { [13] }\end{array}$ & 38 & Placebo & $4-15$ & 10 & $30[28.5]$ & Oral & Monotherapy & 3 & 3 \\
\hline $\begin{array}{l}\text { Levisohn et al, } \\
\text { 2009[14] }\end{array}$ & 64 & Placebo & NA & 20 & $60[53.6]$ & Oral & Polytherapy & 145 & 23 \\
\hline $\begin{array}{l}\text { Pina Garza et al, } \\
\text { 2009[15] }\end{array}$ & 60 & Placebo & $<4$ & $20-25$ & $40-50[45.5]$ & Oral & Polytherapy & 26 & 3 \\
\hline $\begin{array}{l}\text { Glauser et al, } 2006 \\
\text { [16] }\end{array}$ & 101 & Placebo & $4-16$ & 20 & 60 & Oral & Polytherapy & 174 & 22 \\
\hline $\begin{array}{l}\text { Coppola et al, } \\
2006[17]\end{array}$ & 21 & OXC & $3-14$ & 5 & 30 & Oral & Monotherapy & 3 & NA \\
\hline
\end{tabular}

OXC-oxcarbazepine

* Number of children with AEs not stated.

doi:10.1371/journal.pone.0149686.t002 


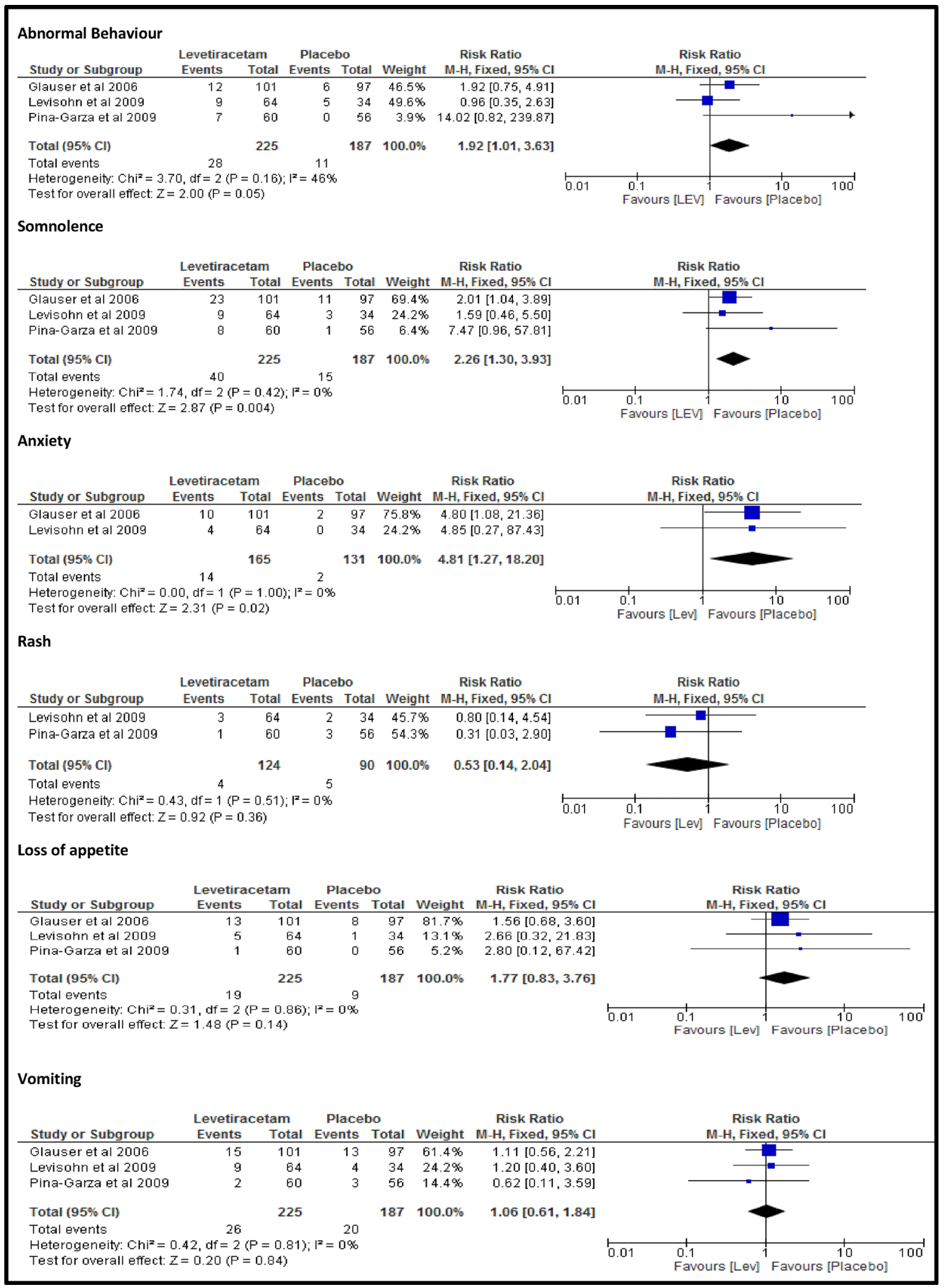

Fig 3. Relative risks of AEs of LEV and placebo.

doi:10.1371/journal.pone.0149686.g003 
Table 3. Prospective cohort studies.

\begin{tabular}{|c|c|c|c|c|c|c|c|c|}
\hline Author (year) & $\begin{array}{l}\text { No } \\
\text { participants }\end{array}$ & $\begin{array}{l}\text { Age } \\
\text { (yrs) }\end{array}$ & $\begin{array}{l}\text { Initial dose (mg/ } \\
\text { kg/day) }\end{array}$ & $\begin{array}{l}\text { Final dose [mean] } \\
\text { (mg/kg/d) }\end{array}$ & Route & Regimen & $\begin{array}{l}\text { No of } \\
\text { AEs }\end{array}$ & $\begin{array}{l}\text { Follow-up } \\
\text { (weeks) }\end{array}$ \\
\hline $\begin{array}{l}\text { Callenbach et al, } 2007 \\
\text { [18] }\end{array}$ & 33 & $4-16$ & 10 & $60[22] \dagger$ & Oral & Polytherapy & 139 & 26 \\
\hline Nakken et al, 2003([19] & 44 & $1-17$ & 10 & 40 & Oral & Polytherapy & $11^{*}$ & 32 \\
\hline $\begin{array}{l}\text { Kanemura et al, } 2013 \\
\text { [20] }\end{array}$ & 61 & $1.3-18$ & 10 & $60[46.1]$ & Oral & Polytherapy & 2 & 24 \\
\hline Chhun et al, 2011[21] & 102 & NA & 10 & $60[31.1]$ & Oral & Polytherapy & 97 & 24 \\
\hline Kim et al, 2014[22] & 55 & $1.1-18.6$ & 10 & $20-80[41.9]$ & Oral & Polytherapy & 21 & 16 \\
\hline Glauser et al, 2002[23] & 24 & $6-12$ & 10 & $40[36.3]$ & Oral & Polytherapy & $70 *$ & 18 \\
\hline Zhang et al, 2014 [24] & 105 & NA & 20 & $30-40$ & NA & Polytherapy & $2^{*}$ & NA \\
\hline Schieman et al, 2012[25] & 103 & $4-16$ & 10 & $100[50.2]$ & NA & Polytherapy & 196 & 48 \\
\hline McTague et al, 2012[26] & 51 & $0.3-18$ & $5-30$ & {$[14.4]$} & IV & Monotherapy & 3 & NA \\
\hline $\begin{array}{l}\text { Weinstock et al, } 2013 \\
\text { [27] }\end{array}$ & 62 & $0.1-16$ & $14->40$ & NA & IV & Monotherapy & 32 & 3 \\
\hline $\begin{array}{l}\text { Furwensteches et al, } \\
2010[28]\end{array}$ & 6 & $<28$ days & 10 & 50 & Oral & Monotherapy & 1 & 90 \\
\hline Feng et al, 2014[29] & 210 & $1-18$ & 10 & 60 & Oral & Monotherapy & $171^{*}$ & 208 \\
\hline Verrotti et al, 2007[30] & 21 & $5-12$ & NA & NA & Oral & Monotherapy & 2 & 52 \\
\hline Verrotti et al, 2009[31] & 12 & $6-16$ & 10 & $20.7-45.2$ & Oral & Monotherapy & 4 & 72 \\
\hline Gao et al, 2008[32] & 32 & $0.7-12$ & 10 & $40[35]$ & NA & Monotherapy & $11^{*}$ & NA \\
\hline Lagae et al, 2005[33] & 77 & $0.5-16$ & 12 & 62[33]† & Oral & Mixed & $12^{*}$ & 20 \\
\hline Dureau et al, 2014[34] & 116 & $<16$ & NA & NA & Oral & Mixed & 15 & 52 \\
\hline $\mathrm{Ng}$ et al, 2010[35] & 30 & $0.5-15$ & NA & $31.1-50.3$ & $\begin{array}{l}\text { IV/ } \\
\text { Oral }\end{array}$ & Mixed & 11 & 4 \\
\hline Ramatani et al, 2010[36] & 38 & $<28$ days & 10 & $45-60$ & IV & Mixed & $2^{*}$ & 52 \\
\hline Li et al, 2011[37] & 129 & $0-16$ & 10 & 60[29]† & NA & Mixed & 97 & 52 \\
\hline
\end{tabular}

doi:10.1371/journal.pone.0149686.t003

The risks of headache, vomiting, hyperactivity and aggression were all lower among monotherapy users $(\mathrm{p}<0.001)$. The only AE significantly more common in association with monotherapy was irritability and there was no difference in the occurrence of somnolence between polytherapy and monotherapy users (Table 5).

\section{Evidence from retrospective studies}

There were 21 retrospective studies (Table A in S1 Table). Similar to reports from prospective studies, both somnolence and abnormal behaviour were the most commonly reported AEs. The majority of the 546 AEs in these studies were psychiatric events (46\%). Seventy eight percent of psychiatric events were behavioural problems. The types of behavioural problems were not specified in many of the studies; however, the commonly reported behavioural problems were aggression (3.8/100) and irritability (1.6/100). Neurological events were also frequently reported (34\%); while only 3\% of AEs were gastrointestinal events (Table B in S1 Table).

\section{Case reports}

There were 16 case reports, with 23 reports of adverse drug reactions (ADRs). The majority of the reported cases were aggravated seizures and psychoses. Other reports included rash, weight 
Table 4. Risk of adverse events occurring in $\geq \mathbf{1 0}$ children from $\mathbf{3 0}$ prospective studies.

\begin{tabular}{|c|c|c|c|c|}
\hline System & Adverse Event & Number of patients & Risk per 100 patients & 95\% Confidence Interval \\
\hline \multicolumn{5}{|l|}{ Psychiatry } \\
\hline \multirow[t]{4}{*}{ Behavioural } & Irritability & 71 & 4.2 & $3.2-5.2$ \\
\hline & Abnormal behaviour & 52 & 3.1 & $2.3-3.9$ \\
\hline & Hyperactivity & 49 & 2.9 & $2.1-3.7$ \\
\hline & Aggression & 44 & 2.6 & $1.9-3.5$ \\
\hline \multirow[t]{4}{*}{ Others } & Dysphoria & 32 & 1.9 & $1.3-2.6$ \\
\hline & Cognitive problems & 23 & 1.4 & $0.8-2.0$ \\
\hline & Anxiety & 29 & 1.7 & $1.1-2.3$ \\
\hline & Learning problem & 11 & 0.7 & $0.3-1.1$ \\
\hline \multicolumn{5}{|l|}{ Nervous } \\
\hline & Somnolence & 142 & 8.4 & $7.1-9.7$ \\
\hline & Headache & 64 & 3.8 & $2.9-4.7$ \\
\hline & Other sleep disorders & 29 & 1.7 & $1.1-2.3$ \\
\hline & Dizziness & 21 & 1.2 & $0.7-1.7$ \\
\hline & Aggravated seizure & 16 & 0.9 & $0.5-1.4$ \\
\hline & Insomnia & 14 & 0.8 & $0.4-1.2$ \\
\hline & Tremor & 11 & 0.7 & $0.3-1.1$ \\
\hline \multicolumn{5}{|l|}{ General } \\
\hline & Loss of appetite & 80 & 4.7 & $3.7-5.7$ \\
\hline & Weakness & 64 & 3.8 & $2.9-4.7$ \\
\hline & Pyrexia & 44 & 2.6 & $1.9-3.5$ \\
\hline & Fatigue & 35 & 2.1 & $1.4-2.8$ \\
\hline \multicolumn{5}{|c|}{ Gastro intestinal } \\
\hline & Vomiting & 50 & 2.9 & $2.1-3.7$ \\
\hline & Abdominal pain & 34 & 2.0 & $1.3-2.7$ \\
\hline & Diarrhoea & 28 & 1.7 & $1.1-2.3$ \\
\hline & Nausea & 14 & 0.8 & $0.4-1.2$ \\
\hline & Gastroenteritis & 10 & 0.6 & $0.2-1.0$ \\
\hline \multicolumn{5}{|l|}{ Respiratory } \\
\hline & Nasopharyngitis & 41 & 2.4 & $1.7-3.1$ \\
\hline & Respiratory tract infection & 36 & 2.1 & $1.4-2.8$ \\
\hline & Cough & 24 & 1.4 & $0.8-2.0$ \\
\hline Skin & Rash & 16 & 0.9 & $0.5-1.4$ \\
\hline
\end{tabular}

doi:10.1371/journal.pone.0149686.t004

loss, depression, autistic regression, acute pancreatitis, elevated alkaline phosphatase, thrombocytopaenia, interstitial nephritis and interstitial lung disease (Table D in S1 Table). The single report of drug interaction was a case of renal failure in a 15 year old boy who received methotrexate for acute lymphoblastic leukaemia [38].

\section{Treatment discontinuation due to adverse drug reactions}

There were 69 reported cases of LEV treatment discontinuation due to ADRs, from a total of 3151 children receiving LEV (2.2\%). Forty five of these were from retrospective studies and 24 from prospective studies. 56 of the 1256 children on polytherapy (4.5\%) and 7 of the 795 receiving monotherapy $(0.9 \%)$ discontinued treatment due to toxicity. Six cases of discontinuation were in studies with mixed (polytherapy and monotherapy) treatment. The discontinuation rates were significantly higher on polytherapy than on monotherapy $(\mathrm{p}<0.001)$. The 
Table 5. Comparison of the most frequent AEs (from 23 prospective studies) among children on polytherapy and monotherapy

\begin{tabular}{|c|c|c|c|}
\hline Adverse event & Poly [n = 786] & Mono[n = 493] & $P$ value \\
\hline Headache & 54 & 9 & $<0.001^{*}$ \\
\hline Vomiting & 47 & 3 & $<0.001 *$ \\
\hline Hyperactivity & 33 & 0 & $<0.001 *$ \\
\hline Aggression & 29 & 3 & $<0.001^{*}$ \\
\hline Pyrexia & 35 & 6 & $0.001^{*}$ \\
\hline Nasopharyngitis & 41 & 0 & $<0.001^{*}$ \\
\hline Respiratory tract infection & 34 & 0 & $<0.001^{*}$ \\
\hline Abdominal pain & 24 & 0 & $<0.001^{*}$ \\
\hline Anxiety & 24 & 0 & $<0.001 *$ \\
\hline Diarrhoea & 28 & 0 & $<0.001 *$ \\
\hline Cough & 24 & 0 & $<0.001^{*}$ \\
\hline Cognitive problems & 19 & 4 & $0.04^{*}$ \\
\hline Drowsiness & 17 & 1 & $0.003^{*}$ \\
\hline Rash & 15 & 1 & $0.008^{*}$ \\
\hline Nausea & 14 & 0 & $0.001^{*}$ \\
\hline Irritability & 26 & 45 & $<0.001^{*}$ \\
\hline Somnolence & 68 & 35 & 0.3 \\
\hline Loss of appetite & 39 & 19 & 0.4 \\
\hline Weakness & 36 & 33 & 0.1 \\
\hline ₹ Abnormal behaviour & 100 & 81 & 0.1 \\
\hline Dizziness & 15 & 3 & 0.1 \\
\hline Aggravated seizure & 11 & 4 & 0.4 \\
\hline
\end{tabular}

\# includes irritability, aggression, hyperactivity and unclassified abnormal behaviours

* Difference is statistically significant.

doi:10.1371/journal.pone.0149686.t005

majority of discontinuation (33 cases, $48 \%$ ) was due to behavioural problems. The nature of the behavioural problems was not stated for 22 cases; there were 6 cases of aggression and 5 of irritability. There were 7 cases of somnolence (10\%) and 6 cases of seizure aggravation (9\%) resulting in treatment discontinuation (Table 6).

\section{Discussion}

This review shows that behavioural problems and somnolence are the most common adverse events to LEV, with behavioural problems being the most common reasons for treatment discontinuation. Compared with placebo, a twofold increase in the risk of abnormal behaviour was reported in children receiving LEV. This is in line with a previous systematic review, which was focused on only behaviour [39]. Behavioural effects seen with LEV treatment could be positive or negative. Examples of positive effects include: increased energy, vigilance, and activity. Aggression, irritability, hyperactivity and nervousness are frequently observed negative effects. Overall, $2.2 \%$ of children receiving LEV had to stop taking the drug due to toxicity. This is similar to the discontinuation rate observed with lamotrigine [40]. When used in combination with another AED, the discontinuation rate was $4.5 \%$.

A systematic review in adults had reported a higher prevalence of anxiety and depression [41]. A prior history of behavioural problem, learning disability and psychiatric conditions can predispose to behavioural decompensation in children on LEV treatment [42]. Behavioural problems associated with LEV have been shown to be worse in epilepsy patients than those 
Table 6. Levetiracetam adverse events leading to treatment discontinuation in prospective and retrospective studies.

\begin{tabular}{ll}
\hline Adverse event & Number of patients \\
\hline Abnormal behaviour & 22 \\
\hline Somnolence & 7 \\
Aggravated seizure & 6 \\
Aggression & 6 \\
Irritability & 5 \\
Rash & 5 \\
Dizziness & 3 \\
Insomnia & 3 \\
Fatigue & 2 \\
Muscle dystrophy & 2 \\
Abdominal pain & 1 \\
Abnormal reflex & 1 \\
Diplopia & 1 \\
Headache & 1 \\
Loss of appetite & 1 \\
Neutropenia & 1 \\
Rectal bleeding & 1 \\
Speech problem & 1 \\
Total & 69 \\
\hline
\end{tabular}

doi:10.1371/journal.pone.0149686.t006

taking the drug for cognitive or anxiety disorders, suggesting that epilepsy itself may be a risk factor for abnormal behaviour [41]. Somnolence was reported in about $9 \%$ of children in this review. Other common neurological effects include headache and dizziness. A twofold increase in the risk of somnolence was observed in children on LEV treatment compared with those given placebo.

Only two RCTs compared the safety of LEV monotherapy with other AEDs $[15,16]$. One other study compared LEV as monotherapy with placebo for two weeks [17]. For ethical reasons, the participants in this study were allowed to exit the study to receive appropriate treatment when a seizure occurred. Although the study was able to establish the short term efficacy of LEV monotherapy, very little information on safety was obtained. There is currently no product license for levetiracetam monotherapy in children less than 16 years old [7]. This is due to the absence of sufficient safety and efficacy data on monotherapy in this age group. Aggregated safety data from 17 prospective studies shows that the risks of AEs were lower with monotherapy treatment than polytherapy. A similar outcome has been reported for AEDs in a previous study [43]. The effect of AED polytherapy on behaviour is complex. Each drug is capable of exerting different behavioural effects. This makes causal attribution of such effects to LEV difficult to establish. Reduction in the number of AEDs or converting to monotherapy treatment generally leads to behavioural improvement [44].

It was not possible to explore the effect of dose on behaviour, because the doses of LEV in children with AEs were not specified in several of the articles. Some authors have suggested that abnormal behaviours in LEV treated patients are idiosyncratic [45]. A previous study among a large cohort of adults who received LEV during preclinical development did not show a significant relationship between dose and behaviour problems [41]. Rapid dose titration rate has however been suggested as a possible risk factor [46]. 
This systematic review has several limitations. The small number of RCTs included in the meta-analysis reduces the strength of evidence. There were no comparator groups for the prospective cohort studies, hence evidence on comparative safety of LEV was not synthesised from these studies. The quality of retrospective studies was not assessed due to lack of validated quality assessment tools; therefore the quality of evidence generated from these retrospective studies is low. In several of the studies, AEs and not ADRs were reported, therefore the causal relationship between LEV and AEs are unknown. The poor reporting of drug toxicity in RCTs of AEDs in children has been noted [47]. In addition, polytherapy RCTs were all add-on studies, which also made causal attribution difficult. Monotherapy studies in newly diagnosed children with epilepsy are necessary to allow comparison of efficacy and toxicity between individual AEDs [43]. This study is also limited by the lack of information on the reporting methods in the individual studies, which makes it impossible to determine the effect of reporting methods on $\mathrm{AE} / \mathrm{ADR}$ reporting.

In conclusion, behavioural problems and somnolence were the most prevalent adverse events to LEV and were the most common cause of treatment discontinuation. Children on polytherapy have a greater risk of adverse events than those receiving monotherapy. There is currently insufficient evidence on the safety of LEV in neonates; therefore more studies in this age group are required.

\section{Supporting Information}

S1 Appendix. SUMARI quality assessment for prospective cohort. (XLSX)

S2 Appendix. PRISMA checklist.

(DOC)

S1 Table. Additional summary tables for prospective studies, retrospective studies and case reports.

(DOCX)

\section{Acknowledgments}

We would like to thank Mohammed Altamimi for assisting with the quality assessment of the articles.

\section{Author Contributions}

Conceived and designed the experiments: OE IC HMS. Analyzed the data: OE. Contributed reagents/materials/analysis tools: OE IC HMS. Wrote the paper: OE IC HMS.

\section{References}

1. Pickrell WO, Lacey AS, Thomas RH, Lyons RA, Smith PE, Rees MI. Trends in the first antiepileptic drug prescribed for epilepsy between 2000 and 2010. Seizure. 2014; 23(1):77-80. doi: 10.1016/j. seizure.2013.09.007 PMID: 24120315

2. Hamer HM, Dodel R, Strzelczyk A, Balzer-Geldsetzer M, Reese J-P, Schöffski O, et al. Prevalence, utilization, and costs of antiepileptic drugs for epilepsy in Germany-a nationwide population-based study in children and adults. J Neurol. 2012; 259(11):2376-84. doi: 10.1007/s00415-012-6509-3 PMID: 22544296

3. Kwong KL, Tsui KW, Wu SP, Yung A, Yau E, Eva F, et al. Utilization of antiepileptic drugs in Hong Kong children. Pediatr Neurol. 2012; 46(5):281-6. doi: 10.1016/j.pediatrneurol.2012.02.019 PMID: 22520348 
4. Lee YJ, Kang H-C, Kim HD, JS L. Efficacy and safety of adjunctive levetiracetam therapy in pediatric intractable epilepsy. Pediatr Neurol. 2010; 42:86-92. doi: 10.1016/j.pediatrneurol.2009.08.002 PMID: 20117743

5. National Institute for Health and Clinical Excellence. The epilepsies: the diagnosis and management of the epilepsies in adults and children in primary and secondary care. 2012; Available from: guidance. nice.org.uk/cg137.

6. UCB Pharma limited. Keppra $250,500,750$ and $1000 \mathrm{mg}$ film-coated Tablets, $100 \mathrm{mg} / \mathrm{ml}$ oral solution and $100 \mathrm{mg} / \mathrm{ml}$ concentrate for solution for infusion: Available from: https://www.medicines.org.uk/emc/ medicine/16231.

7. Pellock JM, Glauser TA, Bebin EM, Fountain NB, Ritter FJ, Coupez RM, et al. Pharmacokinetic study of levetiracetam in children. Epilepsia. 2001; 42(12):1574-9. PMID: 11879369

8. Abou-Khalil B. Levetiracetam in the treatment of epilepsy. Neuropsychiatric disease and treatment. 2008; 4(3):507-23. PMID: 18830435

9. Kastner M, Wilczynski NL, Walker-Dilks C, McKibbon KA, Haynes B. Age-specific search strategies for Medline. J Med Internet Res. 2006; 8(4):e25 PMID: 17213044

10. Higgins JP, Altman DG, Gøtzsche PC, Jüni P, Moher D, Oxman AD, et al. The Cochrane Collaboration's tool for assessing risk of bias in randomised trials. BMJ. 2011; 343: d5928 doi: 10.1136/bmj. d5928 PMID: 22008217

11. Institute JB. System for the Unified Management of the Review and Assessment of Information (SUMARI). The Joanna Briggs Institute. 2004.

12. Borggraefe I, Bonfert $M$, Bast $T$, Neubauer BA, Schotten $K J$, Maßmann $K$, et al. Levetiracetam vs. sulthiame in benign epilepsy with centrotemporal spikes in childhood: A double-blinded, randomized, controlled trial (German HEAD Study). Europ J Paediatr Neurol. 2013; 17(5):507-14.

13. Fattore C, Boniver C, Capovilla G, Cerminara C, Citterio A, Coppola G, et al. A multicenter, randomized, placebo-controlled trial of levetiracetam in children and adolescents with newly diagnosed absence epilepsy. Epilepsia. 2011; 52(4):802-9. doi: 10.1111/j.1528-1167.2010.02976.x PMID: 21320119

14. Levisohn PM, Mintz M, Hunter SJ, Yang H, Jones J. Neurocognitive effects of adjunctive levetiracetam in children with partial-onset seizures: A randomized, double-blind, placebo-controlled, noninferiority trial. Epilepsia. 2009; 50(11):2377-89. doi: 10.1111/j.1528-1167.2009.02197.x PMID: 19702752

15. Piña-Garza JE, Nordli DR Jr, Rating D, Yang H, Schiemann-Delgado J, Duncan B. Adjunctive levetiracetam in infants and young children with refractory partial-onset seizures. Epilepsia. 2009; 50(5):11419. doi: 10.1111/j.1528-1167.2008.01981.x PMID: 19243423

16. Glauser T, Ayala R, Elterman R, Mitchell W, Van Orman C, Gauer L, et al. Double-blind placebo-controlled trial of adjunctive levetiracetam in pediatric partial seizures. Neurology. 2006; 66(11):1654-60. PMID: 16641323

17. Coppola G, Franzoni E, Verrotti A, Garone C, Sarajlija J, Operto FF, et al. Levetiracetam or oxcarbazepine as monotherapy in newly diagnosed benign epilepsy of childhood with centrotemporal spikes (BECTS): an open-label, parallel group trial. Brain Dev. 2007; 29(5):281-4. PMID: 17055681

18. Callenbach P, Arts WFM, ten Houten R, Augustijn P, Gunning WB, Peeters EA, et al. Add-on levetiracetam in children and adolescents with refractory epilepsy: results of an open-label multi-centre study. Europ J Paediatr Neurol. 2008; 12(4):321-7.

19. Nakken KO, Eriksson A-S, Lossius R, Johannessen SI. A paradoxical effect of levetiracetam may be seen in both children and adults with refractory epilepsy. Seizure. 2003; 12(1):42-6. PMID: 12495648

20. Kanemura H, Sano F, Tando T, Sugita K, Aihara M. Efficacy and safety of add-on levetiracetam in refractory childhood epilepsy. Brain Dev. 2013; 35(5):386-91. doi: 10.1016/j.braindev.2012.07.005 PMID: 22871391

21. Chhun S, Troude P, Villeneuve N, Soufflet C, Napuri S, Motte J, et al. A prospective open-labeled trial with levetiracetam in pediatric epilepsy syndromes: continuous spikes and waves during sleep is definitely a target. Seizure. 2011; 20(4):320-5. doi: 10.1016/j.seizure.2010.12.017 PMID: 21256770

22. Kim HJ, Kim SH, Kang H-C, Lee JS, Chung HJ, Kim HD. Adjunctive Levetiracetam Treatment in Pediatric Lennox-Gastaut Syndrome. Pediatr Neurol. 2014; 51(4):527-31. doi: 10.1016/j.pediatrneurol.2014. 06.004 PMID: 25266616

23. Glauser TA, Pellock JM, Bebin EM, Fountain NB, Ritter FJ, Jensen CM, et al. Efficacy and Safety of Levetiracetam in Children with Partial Seizures: An Open-label Trial. Epilepsia. 2002; 43(5):518-24 PMID: 12027913

24. Zhang $Y$, Zhai Q, Tang Z, Zhuo M. [Therapeutic effect of levetiracetam add-on treatment for frontal lobe epilepsy in 105 children]. Nan fang yi ke da xue xue bao. 2014; 34(3):364-7. PMID: 24670450

25. Schiemann-Delgado J, Yang H, de la Loge C, Stalvey TJ, Jones J, LeGoff D, et al. A long-term openlabel extension study assessing cognition and behavior, tolerability, safety, and efficacy of adjunctive 
levetiracetam in children aged 4 to 16 years with partial-onset seizures. J Child Neurol. 2012; 27(1):809. doi: 10.1177/0883073811417183 PMID: 21876066

26. McTague A, Kneen R, Kumar R, Spinty S, Appleton R. Intravenous levetiracetam in acute repetitive seizures and status epilepticus in children: experience from a children's hospital. Seizure. 2012; 21 (7):529-34. doi: 10.1016/j.seizure.2012.05.010 PMID: 22722010

27. Weinstock A, Ruiz M, Gerard D, Toublanc N, Stockis A, Farooq O, et al. Prospective open-label, singlearm, multicenter, safety, tolerability, and pharmacokinetic studies of Intravenous levetiracetam in children with epilepsy. J Child Neurol. 2013; 28(11):1423-9. PMID: 23533164

28. Fürwentsches A, Bussmann C, Ramantani G, Ebinger F, Philippi H, Pöschl J, et al. Levetiracetam in the treatment of neonatal seizures: a pilot study. Seizure. 2010; 19(3):185-9. doi: 10.1016/j.seizure. 2010.01.003 PMID: 20133173

29. Feng XF, Xia ON. Long-term efficacy and tolerability of levetiracetam in different age groups of children with epilepsy: a 210 cases report. Medical Journal of Chinese People's Liberation Army. 2014; 39 (4):324-8

30. Verrotti A, Coppola G, Manco R, Ciambra G, lannetti P, Grosso S, et al. Levetiracetam monotherapy for children and adolescents with benign rolandic seizures. Seizure. 2007; 16(3):271-5. PMID: 17204435

31. Verrotti A, Parisi P, Loiacono G, Mohn A, Grosso S, Balestri P, et al. Levetiracetam monotherapy for childhood occipital epilepsy of gastaut. Acta Neurol Scand. 2009; 120(5):342-6. doi: 10.1111/j.16000404.2009.01264.x PMID: 19754870

32. Gao Z, Jiang Y. Follow-up study on levetiracetam monotherapy in children with epilepsy. Zhongguo dang dai er ke za zhi = Chinese journal of contemporary pediatrics. 2008; 10(6):711. PMID: 19102836

33. Lagae L. Cognitive side effects of anti-epileptic drugs: the relevance in childhood epilepsy. Seizure. 2006; 15(4):235-41. PMID: 16563808

34. Dureau-Pournin C, Pédespan J-M, Droz-Perroteau C, Lavernhe G, Mann M, Pollet C, et al. Continuation rates of levetiracetam in children from the EULEVp cohort study. Europ J Paediatr Neurol. 2014; 18 (1):19-24

35. Ng Y-t, Hastriter EV, Cardenas JF, Khoury EM, Chapman KE. Intravenous levetiracetam in children with seizures: a prospective safety study. J Child Neurol. 2010; 25(5):551-5. doi: 10.1177/ 0883073809348795 PMID: 20413804

36. Ramantani G, Ikonomidou C, Walter B, Rating D, Dinger J. Levetiracetam: safety and efficacy in neonatal seizures. Europ J Paediatr Neurol. 2011; 15(1):1-7.

37. Li J, Xiao N, Chen S. Efficacy and tolerability of levetiracetam in children with epilepsy. Brain Dev. 2011; 33(2):145-51. doi: 10.1016/j.braindev.2010.03.002 PMID: 20359839

38. Parentelli AS, Phulpin-Weibel A, Mansuy L, Contet A, Trechot $P$, Chastagner P. Drug-drug interaction between methotrexate and levetiracetam in a child treated for acute lymphoblastic leukemia. Pediatric blood \& cancer. 2013; 60(2):340-1.

39. Halma E, de Louw AJ, Klinkenberg S, Aldenkamp AP, IJff DM, Majoie M. Behavioral side-effects of levetiracetam in children with epilepsy: A systematic review. Seizure. 2014; 23(9):685-91. doi: 10. 1016/j.seizure.2014.06.004 PMID: 24981629

40. Egunsola O, Choonara I, Sammons HM. Safety of lamotrigine in paediatrics: a systematic review. BMJ Open. 2015; 5(6):e007711 doi: 10.1136/bmjopen-2015-007711 PMID: 26070796

41. Cramer JA, De Rue K, Devinsky O, Edrich $P$, Trimble MR. A systematic review of the behavioral effects of levetiracetam in adults with epilepsy, cognitive disorders, or an anxiety disorder during clinical trials. Epilepsy Behav. 2003; 4(2):124-32. PMID: 12697136

42. Brodtkorb E, Klees TM, Nakken KO, Lossius R, Johannessen SI. Levetiracetam in adult patients with and without learning disability: focus on behavioral adverse effects. Epilepsy Behav. 2004; 5(2):231-5. PMID: 15123025

43. Anderson M, Egunsola O, Cherrill J, Millward C, Fakis A, Choonara I. A prospective study of adverse drug reactions to antiepileptic drugs in children. BMJ Open. 2015; 5(6):e008298. doi: 10.1136/ bmjopen-2015-008298 PMID: 26033949

44. Brodie M, McPhail E, Macphee G, Larkin J, Gray J. Psychomotor impairment and anticonvulsant therapy in adult epileptic patients. Eur J Clin Pharmacol. 1987; 31(6):655-60. PMID: 3830252

45. Dinkelacker V, Dietl T, Widman G, Lengler U, Elger CE. Aggressive behavior of epilepsy patients in the course of levetiracetam add-on therapy: report of 33 mild to severe cases. Epilepsy Behav. 2003; 4 (5):537-47. PMID: 14527496

46. White J, Walczak T, Leppik I, Rarick J, Tran T, Beniak T, et al. Discontinuation of levetiracetam because of behavioral side effects A case-control study. Neurology. 2003; 61(9):1218-21. PMID: 14610123 
47. Anderson M, Choonara I. A systematic review of safety monitoring and drug toxicity in published randomised controlled trials of antiepileptic drugs in children over a 10-year period. Arch Dis Child. 2010; 95 (9):731-8. doi: 10.1136/adc.2009.165902 PMID: 20522477 